\section{Tracking radiation release}

THE wider radiological consequence of the Chernobyl accident may be less fearsome than was at first thought. This at least is the firm opinion of Professor D. Beninson, the Argentinian chairman of the International Commission on Radiological Protection who was the chairman of the appropriate technical session at the Vienna meeting.

The Soviet estimate that $50 \mathrm{MCi}$ (say 2 $\times 10^{17} \mathrm{~Bq}$ ) of radioactivity was released from the reactor in the form of nongaseous fission products, with as much again in the form of noble gases (Ar and $\mathrm{Xe}$ ) and iodine, which is based on measurements of fallout in the Soviet Union, has a formal uncertainty of 50 per cent. By this yardstick, the Chernobyl release was 100 times greater than that from the Windscale reactor fire in 1957 and more than 1,000 times as serious as the Three Mile Island accident two decades later.

So far, the Soviets have calculated only the external radiation doses likely to be incurred elsewhere in the Soviet Union on account of the passage of the radioactive cloud and the continuing effect of radiation from fallout lodged on the ground. The population evacuated from the neighbourhood of Chernobyl is estimated not to have been subjected to doses exceeding 2 rem with some exceptionally-placed individuals receiving between 30 and 35 rem.

For the 135,000 people in the evacuation zone, the collective dose calculated to have been received up to the point of evacuation is 1.6 million man-rem, which would imply an increase in the causation of cancers during the coming decades that would be less than 2 per cent or, using the ICRP estimate of $1.25 \times 10^{-4}$ cases of cancer induction per rem of exposure, a total of fewer than 160 cases.

For the 75 million people in the western regions of the Soviet Union, the collective dose is estimated at 8.6 million man-rem up to the end of 1986 and 29 million manrem over a period of 50 years. The Soviet report is quick to point out that the annual dose to the same population from natural radiation is 10 million man-rem, and that this is a field in which the assumption of a linear dose-response relationship may be least secure. With these reservations, the increased risk of cancer mortality in the western Soviet Union is estimated at less than 0.05 per cent.

The general opinion last week was that these estimates have been reached on conservative assumptions. (One interesing twist is that the frequency of spontaneous cancer, quoted as 10 per cent, is probably lower in the Soviet Union than in the West because of the lesser expectation of life in the Soviet Union.) Some evidence comes from whole-body scanning measurements carried out since the accident.
Estimates of the eventual dose arising from the intake of contaminated food are, by comparison, much less complete. On a calculation of the effect of caesium isotopes, of which 1 million $\mathrm{Ci}$ (of caesium-137) were released, the estimated dosecommitment over 70 years is estimated at
$2.1 \times 10^{8}$ million man-rem for the Ukraine and Byelorussia alone, which would imply an increase of cancer mortality of 0.4 per cent. But there is some experimental evidence, based on whole-body scanning measurements, that the transfer of caesium through the food chain to the bodies of those exposed has not been as efficient as supposed, with measurements roughly 10 per cent of those predicted.

\title{
What really went wrong?
}

Richard Wilson, author of an American Physical Society report on reactor safety, reflects on the lessons of Chernobyl.

LAST week's post-accident review meeting was historic for two reasons. It is the first time that there has been a nuclear power accident of the severity that we have all feared and it's also, perhaps, the first time since Ivan the Terrible that the Russians have discussed so openly the details of a domestic disaster. I believe that the second is the more important. Indeed, analysis of the event suggests that a primary cause of the accident was a lack of communication within the Soviet system. The meeting was therefore particularly difficult and important for the Soviets.

The Soviet delegation reporting on the Chernobyl catastrophe is led by Academician Legasov and includes Academician Ilyin, who directed the handling of the evacuation and subsequent study of radiological consequences; Dr Angelina Gusk'ova, who was in charge of most of the patients with radiation sickness; and many others directly responsible for various aspects of the disaster. This compostion shows an unusual seriousnes about reporting, helping and seeking help from the international technical community. The only notable exception was the absence of people who had operated RMBK-1000 reactors. The Soviets have worked fast since 26 April. Their report, hastily assembled though it is, is a monumental and impressive document. I, at least, would be proud to have been an author.

The Soviet RMBK-1000 reactors use a graphite moderator to slow down the neutrons, with uranium oxide fuel rods inside distinct vertical channels arranged in a lattice. Through the channels, coolant water flows and boils. There are two features to this reactor that are significant for major accidents. The first is that the moderator is solid and separate from the coolant. Removal of the liquid coolant, due to boiling, will not shut down the reactor. If other engineered design features fail to shut the reactor before an impending accident, the graphite and uranium must mechanically separate - and the ejection of an appreciable fraction of the fuel seems to be what terminated the nuc-

\section{lear reaction at Chernobyl 4 .}

The other feature is that, in this reactor, removal of water in the channel (perhaps by an increase in steam content) leads to an increase of reactivity, a power increase, further boiling and removal (voiding) of water. Technically the reactor is then said to have a positive void coefficient of reactivity.

Of course this tendency to instability can be stopped by an engineered safety device - introducing boron absorber (control) rods to reduce reactivity faster than channel voiding increases it. Physicists prefer inherently safe devices, but admit the possibility of safe engineered devices, if proper attention is paid to them. This proper attention was not paid at Chernobyl and, in fact, the RMBK reactors have the worst shut-down capability of any commercial reactor in the world.

The control rods move quite slowly and, if in the "out" position, cannot reach the active zone, and so affect reactivity, for a few seconds. The designers therefore established a rule: at least 30 rods must be in the core at any time. Because view of the crucial importance of an engineered shut-down (scram) in this reactor, leaving this safety precaution to a rule, rather than a mechanical limit, or interlock, seems unwise.

At the power plant. an experiment had been planned to tell for how long a generator could contine to generate enough electricity to operate important systems after the steam to the turbine is cut off. There were delays; in order to allow the experment to go ahead, the operators deliberately violated six safety rules. Two of these made the reactor exceptionally difficult to control and intensified the effect of the positive void coefficient. The coolant water was near saturation, so that a small change in hydraulic conditions could rapidly change the void fraction and thus the reactivity. These put the reactor time constant as low as a second, falling rapidly as a prompt critical situation was reached.

The reactor is not designed to control such small time constants. In three different ways, the operators disconnected the automatic reactor shut-down devices so that they could continue to operate in this unsafe condition. This meant that the 